\title{
Pure tocotrienol CONCENTRATE PRotected RAT GASTRIC MUCOSA FROM ACUTE STRESS-INDUCED INJURY BY A NON-ANTIOXIDANT MECHANISM
}

\author{
Mohd Nor Syidiq Rodzian ${ }^{1}$, Ibrahim Abdel Aziz Ibrahim ${ }^{2}$, Nur Azlina Mohd Fahami \\ NAFEEZA MOHD ISMAIL ${ }^{1}$
}

\begin{abstract}
${ }_{1}$ Department of Pharmacology, Faculty of Medicine, Universiti Teknologi MARA, Shah Alam, Selangor, Malaysia 2Department of Pharmacology, Faculty of Medicine, Universiti Teknologi MARA, Shah Alam, Selangor, Malaysia; Department of Pharmacology and Toxicology, Faculty of Medicine, Umm Al-Qura University, Makkah, Saudi Arabia 3 Department of Pharmacology, Faculty of Medicine, Universiti Kebangsaan Malaysia, Malaysia
\end{abstract}

\begin{abstract}
Stress has been implicated as a risk factor of various major health problems, such as stress-induced gastric mucosal injury. This study was performed to investigate the action of a pure preparation of tocotrienol (T3) concentrate, made up of $90 \% \delta$-tocotrienol and $10 \% \gamma$-tocotrienol, on gastric injury of rats induced by water-immersion restraint stress (WIRS). Fourteen male Sprague-Dawley rats (200-250 g) were divided into two equal groups: a control group and a treated group. The treatment group received T3 concentrate at $60 \mathrm{mg} / \mathrm{kg}$ body weight daily for 28 days. The body weights of rats were recorded daily before the treatment was given. At the end of the treatment period, all rats were subjected to WIRS for 3.5 hours, following which the rats were euthanized. The stomachs were isolated and opened along the greater curvature for the examination of lesions and measurements of gastric malondialdehyde (MDA) and prostaglandin $\mathrm{E}_{2}\left(\mathrm{PGE}_{2}\right)$ contents. The mean gastric mucosal lesion index in the treated rats was significantly lower than that in the control rats. This suggests that the T3 concentrate has the ability to confer protection to the gastric mucosa against gastric injury induced by acute stress. No significant difference was observed for changes in body weight before and after the treatment. The gastric $\mathrm{PGE}_{2}$ content in both groups was comparable. However, the gastric MDA content was significantly higher in the treated group compared to the control group, indicating that the $\mathrm{T} 3$ supplementation was not able to reduce the lipid peroxidation process. This study concludes that the $\mathrm{T} 3$ concentrate has the ability to protect the gastric mucosa from stress-induced injury by a non-antioxidant mechanism.
\end{abstract}

Key words: tocotrienol, water-immersion restraint stress, gastric injury, malondialdehyde, prostaglandin $\mathrm{E}_{2}$.

\section{Introduction}

It is well known that stress has been implicated as a risk factor of various major health problems [1-3]. In particular, this includes the formation of gastric lesions, also known as stress-induced gastric mucosal injury (SIGMI) [4]. Among various animal models of stress, water-im- mersion restraint stress (WIRS) has been widely accepted for studying SIGMI. Previous studies demonstrated the immediate appearance of multiple gastric lesions in the gastric mucosa in rats subjected to WIRS for 3.5 hours [5-8], confirming the reproducibility of this model.

The pathological basis for the development of stress-induced gastric injury is multifactorial. Stress has 
been shown to cause overstimulation of the sympathetic activity and activation of the hypothalamic-pituitary adrenal axis (HPA axis) leading to hypersecretion of catecholamines [9]. The increased catecholamine levels result in direct vasoconstriction of gastric mucosal vessels, which in turn leads to local hypoxia and ischaemia. Under this hypoxic-ischaemic condition, reactive oxygen species (ROS) such as superoxide anion, hydrogen peroxide and hydroxyl radical are rapidly generated [7].

These ROS are believed to be cytotoxic and mediate tissue damage by degrading the polyunsaturated fatty acids of the cellular membranes through the lipid peroxidation process. Furthermore, it has been postulated that the oxygen-derived free radicals and lipid peroxidation are involved in the pathogenesis of SIGMI [10]. In addition, the development of SIGMI may be enhanced by factors such as impairment of gastric microcirculation, increased lipid peroxidation and increased pro-inflammatory cytokines and other mediators such as prostaglandin E2 [11].

Tocotrienols are essential forms of vitamin $\mathrm{E}$ that are structurally different from tocopherol. Since it was first discovered by Pennock et al. in 1964, a number of health-related biological properties of tocotrienol have been identified, including the property of gastric protection [12]. It was also postulated that tocotrienols are more potent antioxidants compared to tocopherol and this is due to their higher tendency to react with lipid radicals in the membrane. Supplementation with vitamin $E$ such as $\alpha$-tocopherol and mixed tocotrienol isomers protects the gastric mucosa against stress-induced injury. It was also postulated that tocotrienol possesses a better protective effect compared with tocopherol and this was related to a decrease in lipid peroxidation, restoration of glutathione peroxidase enzyme levels and also increased gastric prostaglandin $\mathrm{E}_{2}[7,10,13]$. Furthermore, the $\delta$-tocotrienol form of tocotrienol was found to be more potent than the $\gamma$ - and $\alpha$-tocotrienol forms [14].

Oxidative stress plays an important role in the pathogenesis of stress-induced gastric injury. Hence, the effects of tocotrienol on oxidative stress could reduce the effects of acute stress-induced gastric injury. Therefore, this study was designed and carried out to study the gastro-protective effects of the most potent isoform of tocotrienol, $\delta$-tocotrienol, on stress-induced gastric mucosal injury.

\section{Material and methods}

In this study, male Sprague-Dawley rats with initial weight of 200 to $250 \mathrm{~g}$ were used. They were obtained from the Laboratory Animal Care Unit (LACU), Faculty of Medicine, Universiti Teknologi MARA (UiTM). The rats were kept in polycarbonate cages, and given food and water ad libitum with exposure to a regular night and day cycle (daylight from 7.00 am to $5.00 \mathrm{pm}$ ). The rats were fed twice daily (morning and afternoon around 8.00 am and $4.00 \mathrm{pm}$ ) and treatment was given once daily around $9.00 \mathrm{am}$. The daily diet was normal rat chow purchased from Gold Coin, Malaysia. The tocotrienol concentrate consisting of $\delta$-tocotrienol and $\gamma$-tocotrienol (DeltaGold 70) was supplied by American River Nutrition Inc., USA. Olive oil (Filippo Berio, Italy) was used as the vehicle and also placebo.

All the rats in the treatment group were given supplementation of $\delta$-tocotrienol at $60 \mathrm{mg} / \mathrm{kg}$ body weight. This dose was chosen based on previous studies which had reported protective effects of tocotrienol and tocopherol on stress-induced gastric mucosal injury [9, 10, 15]. The DeltaGold 70 used in this study was in the form of $70 \%$ viscous tocotrienol material). Therefore, the $\delta$-tocotrienol concentrate was diluted with olive oil as the vehicle (8.6 $\mathrm{g}$ of DeltaGold 70 was dissolved in $100 \mathrm{ml}$ of olive oil).

The study design consists of 14 male Sprague-Dawley rats (200-250 g) which were divided into two equal sized groups. Group 1 or the tocotrienol group was given $\delta$-tocotrienol (DeltaGold 70) at the dose of $60 \mathrm{mg} / \mathrm{kg}$ body weight via oral gavage for 28 days. Group 2 or the control group was administered only olive oil via oral gavage for the same treatment period. The rats were deprived of food overnight before they were exposed to stress. On day 28, both groups were subjected to water immersion stress (WIRS) for 3.5 hours. The WIRS was applied according to the procedure described by Ibrahim et al. Water-immersion restraint stress was conducted by placing each rat in a plastic restrainer individually. The restrainer was then immersed neck-deep in a beaker filled with water at room temperature $\left(23^{\circ} \mathrm{C}\right)$, for 3.5 hours $[7,16]$.

After exposure to stress, the rats were anaesthetized with diethyl ether and blood was drained by cardiac puncture to euthanize the rats. This was followed by a laparotomy and the stomach was isolated. The isolated stomach was dissected along the greater curvature to open it and was pinned to a white cork material with the mucosal surface exposed or facing upwards. The stomach surface was then lightly washed with distilled water before it was photographed for the assessment of gastric lesions.

\section{Assessment of gastric lesions}

The assessment of severity of gastric lesions was done based on a modified semi-quantitative scale [10]. The severity of gastric lesions was assessed macroscopically by two independent examiners who were blinded to the treatment that the rats received. The scale used was such as in Table I. 
Table I. Gastric lesion scale

\begin{tabular}{cl}
\hline SCORE & DesCription Of GASTRIC LESIONS \\
\hline 0 & None (normal mucosa) \\
\hline 1 & Presence of distinct lesions in $\leq 25 \%$ of the gastric mucosa \\
\hline 2 & Presence of distinct lesions in $\leq 50 \%$ of the gastric mucosa \\
\hline 3 & Presence of distinct lesions in $\leq 75 \%$ of the gastric mucosa \\
\hline 5 & Presence of a single continuous lesion extending $\geq 25 \% \leq 50 \%$ of the gastric mucosa \\
\hline 6 & Presence of a single continuous lesion extending $>50 \%$ of the gastric mucosa \\
\hline 7 & Presence of multiple continuous lesions extending $\geq 25 \% \leq 50 \%$ of the gastric mucosa \\
\hline
\end{tabular}

\section{Measurement of gastric malondialdehyde content}

Malondialdehyde (MDA), a stable secondary product of lipid peroxidation, was estimated according to the method described by Ledwozyw et al. (1986). Measurement of MDA was based on the colorimetric reaction between MDA and thiobarbituric acid (TBA) under high temperature $\left(90-100^{\circ} \mathrm{C}\right)$ and acidic conditions [17].

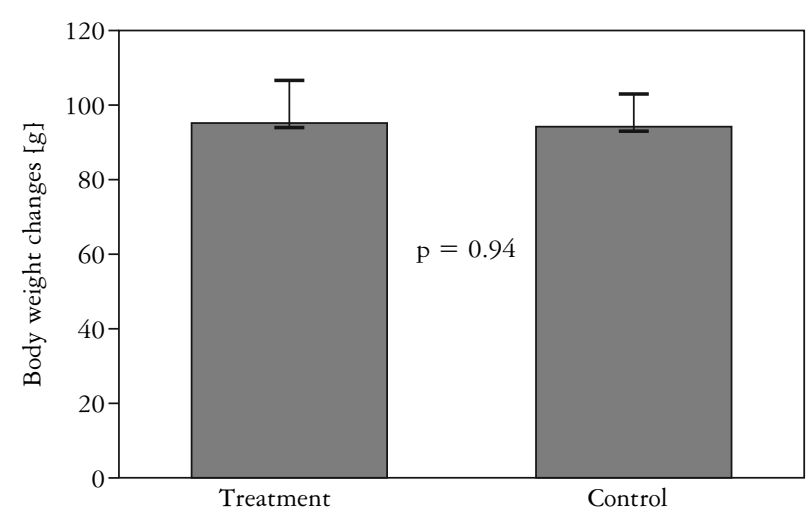

Fig. 1. Mean rats' weight changes

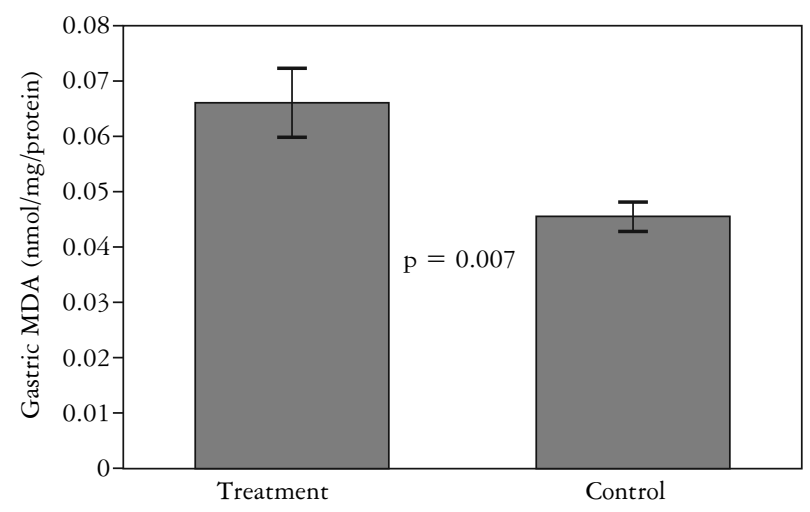

Fig. 2. Mean gastric malondialdehyde concentration

\section{Measurement of gastric prostaglandin $E_{2}$ content}

Prostaglandin $\mathrm{E}_{2}\left(\mathrm{PGE}_{2}\right)$ is a primary product of arachidonic acid metabolism in many cells and is one of the main mediators of gastric mucosal protection. In this study, measurement of gastric $\mathrm{PGE}_{2}$ was performed using the $\mathrm{PGE}_{2}$ Express Enzyme Immuno Assay (EIA) kit (Cayman Chemical Company, USA catalogue no. 500141).

\section{Statistical analysis}

Statistical analysis was carried out using the SPSS statistical package version 19 (SPSS Inc. USA). Normal distribution of all variables was examined by KolmogorovSmirnov test. The results showed that all variables were normally distributed. The results are expressed as mean + SEM. Statistical significance $(\mathrm{p}<0.05)$ was determined by independent Student's t-test.

\section{Results}

\section{Effect of $\delta$-tocotrienol on body weight of rats}

Rats in both groups showed an increase in body weight after 28 days of treatment with $\delta$-tocotrienol and placebo. The mean body weight change for rats treated with $\delta$-tocotrienol and placebo was found to be $95.5 \pm 11.130 \mathrm{~g}$ and $94.5 \pm 8.874 \mathrm{~g}$ respectively. No significant difference was observed in the rats' weight gain between these two groups $(\mathrm{p}=0.942)$. This indicates that $\delta$-tocotrienol may not have any effects on body weight, as shown in Fig. 1.

\section{Effect of $\delta$-tocotrienol on the concentration of gastric malondialdehyde contents}

The concentration of gastric tissue MDA was found to be $0.04549 \pm 0.00256 \mathrm{nmol} / \mathrm{mg} /$ protein and $0.06612 \pm 0.00610 \mathrm{nmol} / \mathrm{mg} /$ protein in the control group and $\delta$-tocotrienol treated group respectively, as shown in Fig. 2. The concentration of gastric tissue MDA in the $\delta$-tocotrienol treated group was found to 
be $45 \%$ higher than that of the control group. Malondialdehyde was significantly higher in rats that were treated with $\delta$-tocotrienol compared with the control group $(\mathrm{p}<0.007)$. This shows that supplementation with $\delta$-tocotrienol was not able to reduce the lipid peroxidation in rats subjected to WIRS for 3.5 hours.

\section{Effect of $\delta$-tocotrienol on gastric prostaglandin $\mathbf{E}_{2}$ content}

The mean gastric $\mathrm{PGE}_{2}$ concentration was found to be $1056.794 \pm 66.034 \mathrm{pg} / \mathrm{ml}$ and $995.792 \pm 147.092$ $\mathrm{pg} / \mathrm{ml}$ in the control group and treated group respectively. The $\mathrm{PGE}_{2}$ concentration of gastric tissue in the $\delta$-tocotrienol treated group was found to be $6 \%$ lower than that of the control group, as shown in Fig. 3. When the mean PGE2 concentration in both groups was compared, no significant difference was observed between these groups $(p=0.712)$. This shows that supplementation with $\delta$-tocotrienol had no effect on gastric $\mathrm{PGE}_{2}$.

\section{Effect of $\delta$-tocotrienol on stress-induced gastric mucosal injury (SIGMI)}

The results of our study showed that the mean lesion score in rats treated with $\delta$-tocotrienol and placebo was $2.43 \pm 1.21$ and $5.29 \pm 0.81$ respectively. The mean lesion score in the $\delta$-tocotrienol treated group was found to be $117 \%$ lower than that of the control group. When the mean lesion scores in both groups were compared, the lesion score of control rats was found to be significantly higher in rats that were treated with $\delta$-tocotrienol $(\mathrm{p}<0.05)$, as shown in Fig. 4.

Figure $5 \mathrm{~A}$ illustrates the reduced formation of gastric haemorrhagic lesions in one of the rats supplemented with $\delta$-tocotrienol but Fig. 5B demonstrates distinct lesions with small spots of petechiae on gastric mucosa of rats which received the same treatment. Extensive haemorrhagic lesions covering more than $50 \%$ of the gastric mucosal surface of rats treated with placebo are shown in Fig. 5D. Figure 5D shows multiple haemorrhagic streaks on gastric mucosa of a rat in the control group. The results of our study showed that supplementation with $\delta$-tocotrienol was able to partially reduce the severity of gastric lesions.

\section{Discussion}

Acute stress was demonstrated to consistently produce stress-induced gastric mucosal injury [7, 9, 15]. In the present study, WIRS produced remarkable haemorrhagic gastric lesions. It was found that WIRS increased gastric contractions [15] and later this would cause impaired gastric blood flow to the mucosa and produce ischaemic damage, resulting in the development of gastric lesions [18].

Antioxidants such as vitamin E play an important role in the regulation of body weight, as shown in previous stud- ies [19-21]. Variable effects of palm vitamin E (PVE) have been reported, whereby some increase, and others decrease body weight [22]. According to Qureshi et al., the discrepancies between the findings above may have been due to the supplement preparation being different in each study [23]. In the study of Khan et al., the preparation of PVE consisted of $30 \%$ tocopherols and $70 \%$ tocotrienols while Qureshi's study used a preparation of TRF (4.5\% $\alpha$-tocopherol and $\sim 95 \%$ tocotrienol), $\gamma$-tocotrienol, desmethyl, and didesmethyl tocotrienols $[22,23]$. It is possible that the significantly increased body weight as in Khan's study (2011) could be due to higher levels of tocopherols present in the treatment preparation [22]. The findings of our present study demonstrated that the gain in body weight in rats supplemented with pure $\delta$-tocotrienol was not significantly different from the control group supplemented with placebo. This indicates that $\delta$-tocotrienol may not have effects on regulating body weight of rats. The finding is consistent with the study by Nur Azlina et al. (2005c), who reported that supplementation with different forms of vitamin E, tocopherol and tocotrienol was unable to prevent the drop in body weight of rats fed with a vitamin E deficient diet [21]. Therefore, we suggest that supplementation with vitamin $\mathrm{E}$ in rats might not be effective in regulating body weight.

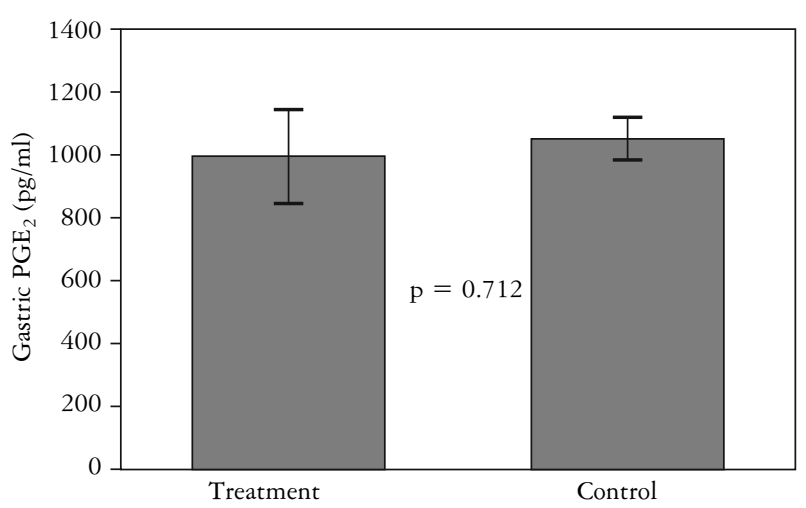

Fig. 3. Mean gastric prostaglandin $\mathrm{E}_{2}$ concentration

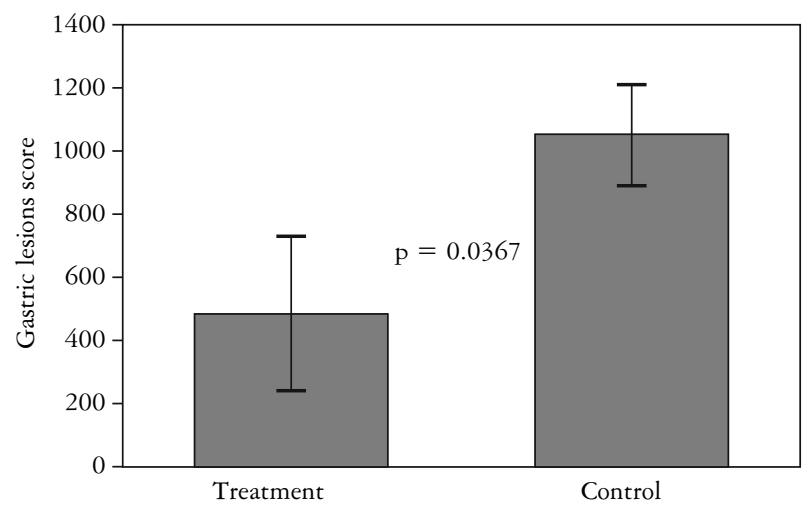

Fig. 4. Mean gastric lesion score 

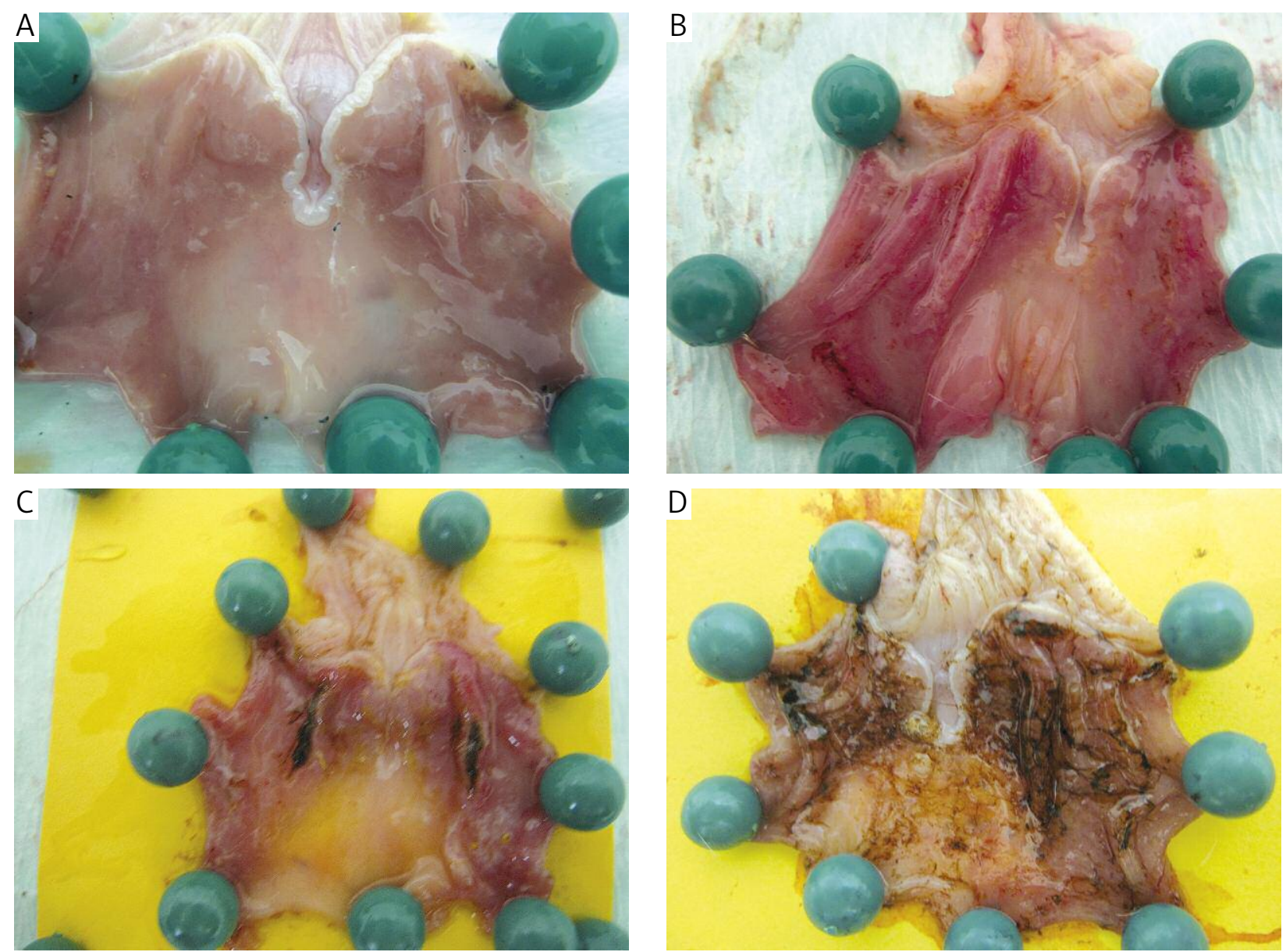

Fig. 5. A - Generalized hyperaemia with absence of gastric lesions. B - Distinct lesions with small spots of petechiae. C - Multiple haemorrhagic lesion streaks. D - Extensive haemorrhage with gastric lesion covering more than $50 \%$ of mucosal surface

Among various animal models of stress, restraint or immobilization stress on rats has yielded the most reproducible results and is a commonly used and clinically relevant model for stress ulceration. The WIRS method of inducing gastric lesions was first described by Takagi and Okabe (1968) [24]. Following that, the WIRS method was used widely by investigators to demonstrate the appearance of multiple gastric lesions in the gastric mucosa in rats, confirming its reproducibility $[7,25-27]$. Hence, it remains relevant as a reliable model for use in studies related to SIGMI.

Supplementations of vitamin E such as tocopherol and tocotrienol have been shown to reduce the formation of SIGMI as reported in previous studies $[10$, 28]. The findings were observed in the study by Ibrahim et al. which showed a significant reduction in mean gastric lesions in rats supplemented with PVE and $\alpha$-tocopherol (60 mg/kg body weight for 28 days) [7]. This is consistent with the findings in the present study which have shown that pure $\delta$-tocotrienol was able to protect the gastric mucosa against SIGMI.

Mechanisms of protection of tocotrienol against SIGMI remain unclear. In previous studies [7, 10, 28] it was suggested that tocotrienol's protective effects on gastric mucosa were related to its ability to reduce lipid peroxidation. These findings were contradictory to the present findings where it was found that $\delta$-tocotrienol had no effect on lipid peroxidation, which suggests that its ability to reduce SIGMI is mediated through a non-antioxidative effect. In support of a non-antioxidative effect, the present study found that $\delta$-tocotrienol demonstrated potential in reducing $\mathrm{PGE}_{2}$. Prostaglandin $\mathrm{E}_{2}$ produced under stress conditions results from activation of COX-2 enzyme and therefore its function is more as an inflammatory mediator in the gastric mucosa rather than gastroprotective. As discussed earlier, it is possible that $\delta$-tocotrienol has COX-2 suppressive effects.

There are a few possibilities to explain the dose-related discrepancies in pharmacological effects. The dose that was used in this study, $60 \mathrm{mg} / \mathrm{kg}$ body weight, may have been in a range that converted it to a prooxidant compound. The doses used in previous studies were $150 \mathrm{mg}$ and $300 \mathrm{mg}$ per $\mathrm{kg}$ of food and treatment was continued for 8 weeks. Rats that were fed with the lower dose had a lower content of gastric tis- 
sue MDA, and ICAM expression [29, 30]. There are also some data suggesting that high doses of $\gamma$-tocotrienol are partly converted to $\alpha$-tocopherol [31]. As such, this may explain the effect seen in our study.

The main mechanisms that mediate protection by $\mathrm{PGE}_{2}$ on gastric mucosa are through increasing their secretion of gastric bicarbonate and mucus secretions $[32,33]$. In addition, it is involved in the maintenance of gastric blood flow [34] and it has recently been demonstrated that $\mathrm{PGE}_{2}$ stimulates healing of gastrointestinal tract lesions by stimulating angiogenesis by the upregulation of VEGF expression [35]. Prostaglandin $\mathrm{E}_{2}$ is also known for its inhibitory effects on acid secretion. All the aforementioned effects are a result of activation of COX-1 enzyme, the constitutive isoform which is responsible for various housekeeping or physiological roles [36]. The reduction in $\mathrm{PGE}_{2}$ content caused by stress was also confirmed in more recent studies [7, 10]. Brzozowski et al. previously suggested that the deficient $\mathrm{PGE}_{2}$ generation in the gastric mucosa following WIRS may lead to upregulated expression of COX-2 mRNA [37].

Other studies suggest that the protective effects of PVE against stress-induced gastric injury may partly be due to their abilities to increase gastric $\mathrm{PGE}_{2}$ content $[7,10,37]$. However, the unaltered levels of $\mathrm{PGE}_{2}$ in this work may be due to the different vitamin $\mathrm{E}$ preparation used. The vitamin $\mathrm{E}$ used in the study by Ibrahim et al. was PVE which contained approximately $70 \%$ tocotrienols and 30\% tocopherols, whereas our study used a pure concentrate of $\delta$-tocotrienol [7]. Nur Azlina $e t$ al. reported that supplementation with a pure concentrate of palm tocotrienols had no impact on gastric $\mathrm{PGE}_{2}$ content in stressed rats [13]. However, there was an improvement in the severity of SIGMI in the study by Nur Azlina et al. [10]. The rise in $\mathrm{PGE}_{2}$ levels may be attributable to the tocopherols present in the treatment preparations in previous works.

Based on our findings with support from previous studies, we hypothesize that the lower levels of $\mathrm{PGE}_{2}$ in the tocotrienol-treated group reflects down-regulation of COX-2 expression. This hypothesis needs to be addressed in future studies. In the context of inflammation, in previous studies PVE has been shown to suppress the transcription of pro-inflammatory cytokines, blocking the expression of COX-2, but not COX-1. It was reported that $\gamma$-tocopherol inhibited the production of $\mathrm{PGE}_{2}$ in human lung epithelial A5 49 cells activated by interleukin- $1 \mathrm{~b}$. This effect was, however, not seen with $\alpha$-tocopherol [38]. Another study demonstrated that $\gamma$-tocotrienol, but not tocopherol, is a potent inhibitor of nuclear factor- $\mathrm{KB}(\mathrm{NF}-\kappa \mathrm{B}) \mathrm{ac}-$ tivation that leads to the down-regulation of various gene products including COX-2 [39].

In a study such as ours, using $\delta$-tocotrienol may have down-regulated COX-2 expression which led to lower content of $\mathrm{PGE}_{2}$. The onset of inhibitory action of $\delta$-tocotrienol on activated COX-2 is not known. The other factor that has to be considered to explain why $\mathrm{PGE}_{2}$ was not significantly reduced is the probable conversion of $\delta$-tocotrienol to $\alpha$-tocopherol. Production of PGE2 varied in different reports according to the type of tocopherol $[38,40,41]$. In a study by Mun et al. using an LPS-stimulated model, $\delta$-tocotrienol was shown to be the most effective isoform of vitamin $\mathrm{E}$ causing suppression of $\mathrm{PGE}_{2}$ and at the same time inhibiting the expression COX-2 [42].

In conclusion, the results of the present study suggest that pure $\delta$-tocotrienol has the ability to reduce the severity of SIGMI. Supplementation of rats with pure $\delta$-tocotrienol markedly reduced the mean gastric lesion score compared to the control group. However, the exact mechanism of protection produced by this vitamin $\mathrm{E}$ isomer remains unclear. We have suggested that $\delta$-tocotrienol may exert non-oxidative protection on the stress-induced gastric injury. It was found that $\delta$-tocotrienol was unable to reduce the lipid peroxidation process and has no effect on gastric $\mathrm{PGE}_{2}$ content. Supplementation of rats with $\delta$-tocotrienol results in a significant rise in the gastric MDA compared with the control group. Moreover, no significant difference was observed in the gastric $\mathrm{PGE}_{2}$ content between these two groups. In this study, it was also found that $\delta$-tocotrienol produced no significant difference in rats' weight gain between the treated and the control group. Therefore, we have suggested that $\delta$-tocotrienol's effect on this parameter may be dose-dependent. Further studies to elucidate the optimum doses of $\delta$-tocotrienol $\mathrm{E}$ on body weight and other gastric parameters are warranted.

\section{The authors declare no conflict of interest.}

\section{References}

1. Vere CC, Streba CT, Streba LM, et al. Psychosocial stress and liver disease status. World J Gastroenterol 2009; 15: 2980-2986.

2. Kane PP. Stress causing psychosomatic illness among nurses. Indian J Occup Environ Med 2009; 13: 28-32.

3. Tawatsupa B, Lim LL, Kjellstrom T, et al.; The Thai Cohort Study Team. The association between overall health, psychological distress, and occupational heat stress among a large national cohort of 40,913 Thai workers. Glob Health Action 2010; 3: 5034-5044.

4. Konturek PC, Brzozowski T, Konturek SJ, et al. Activation of genes for growth factors and cyclooxygenases in rat gastric mucosa during recovery from stress damage. Eur J Pharmacol 1998; 342: 55-65.

5. Konturek SJ, Brzozowski T, Pajdo R, et al. Gastric preconditioning induced by short ischemia: the role of prostaglandins, nitric oxide and adenosine. Med Sci Monit 2001; 7: 610-621.

6. Goto H, Tachi K, Hisanaga Y, et al. Exacerbatory mechanism responsible for water immersion stress-induced gastric lesions in aged rats compared with young rats. Clin Exp Pharmacol Physiol 2001; 28: 659-662.

7. Ibrahim IA, Yusof K, Ismail NM, Fahami NA. Protective effect of palm vitamin $E$ and $\alpha$-tocopherol against gastric lesions induced by water immersion restraint stress in Sprague-Dawley rats. Indian J Pharmacol 2008; 40: 73-77. 
8. Chen CY, Kuo TL, Sheu SY, Kuo TF. Preventive effects of Chinese herb chai-hu-gui-zhi-tang extract on water immersion restraint stress-induced acute gastric ulceration in rats. J Vet Med Sci 2010; 72: 679-685.

9. Aziz Ibrahim IA, Kamisah Y, Nafeeza MI, Nur Azlina MF. The effects of palm vitamin $\mathrm{E}$ on stress hormone levels and gastric lesions in stress-induced rats. Arch Med Sci 2012; 8: 22-29.

10. Nur Azlina MF, Rubaizah K, Siti Muliana M, Nafeeza MI. Modulation of restraint induced gastric oxidative changes in rats by tocotrienol and tocopherol. Inter J Pharm 2009; 5: 58-64.

11. Konturek PC, Brzozowski T, Burnat G, et al. Gastric ulcer healing and stress-lesion preventive properties of pioglitazone are attenuated in diabetic rats. J Physiol Pharmacol 2010; 61: 429-436

12. Pennock JF, Hemming FW, Kerr JD. A reassessment of tocopherol in chemistry. Biochem Biophys Res Commun 1964; 17: 542-548.

13. Azlina MF, Nafeeza MI, Khalid BA. A comparison between tocotrienol and tocopherol effects on gastric parameter in rats exposed to stress. Asia Pac J Clin Nutr 2005a; 14: 358-365.

14. Palozza P, Verdecchia S, Avanzi L, et al. Comparative antioxidant activity of tocotrienols and the novel chromanyl-polyisoprenyl molecule FeAox- 6 in isolated membranes and intact cells. Mol Cell Biochem 2006; 287: 21-32.

15. Ibrahim IA, Kamisah Y, Nafeeza MI, Nur Azlina MF. Modulation of gastric motility and gastric lesion formation in stressed rats given enteral supplementation of palm vitamine $\mathrm{E}$ and $\alpha$-tocopherol. Inter Med J 2011; 18: 47-52.

16. Nishida K, Ohta Y, Kobayashi T, Ishiguro I. Involvement of the xanthine-xanthine oxidase system and neutrophils in the development of acute gastric mucosal lesions in rats with water immersion restraint stress. Dig 1997; 58: 340-351.

17. Ledwozyw A, Michalak J, Stepien A, Kadziolla A. The relationship between plasma triglycerides, cholesterol, total lipid peroxidation product during human atherosclerosis. Clin Chem Acta 1986; 155 : 275-284.

18. Brzozowski T, Konturek PC, Sliwowski Z, et al. Gastroprotective action of orexin-A against stress-induced gastric damage is mediated by endogenous prostaglandins, sensory afferent neuropeptides and nitric oxide. Regul Pept 2008; 148: 6-20.

19. Ima-Mirwana S, Norazlina M, Khalid BA, Gapor MT. Vitamin E deficiency impairs weight gain in normal and ovariectomised growing female rats. Med J Islam Acad Sci 1998; 11 : 99-105.

20. Azman A, Khalid Bak, Ima-Mirwana S. The effects of vitamin $\mathrm{E}$ on bodyweight and fat mass in intact and ovariectomized female rats. Med J Islam Acad Sci 2001; 14: 125-138.

21. Nur Azlina MF, Nafeeza MI, Khalid BA. Effects of vitamin E on food intake and body weight in rats exposed to restraint stress. Med J Islam Acad Sci 2005c; 15: 81-86.

22. Khan A, Chandell AS, Ishaq F, et al. Hypolipidemic effects and antioxidant activity of tocotrienols on cigarette smoke exposed rats. Der Chemica Sinica 2011; 2: 211-222.

23. Qureshi AA, Pearce BC, Nor RM, et al. Dietary alpha-tocopherol attenuates the impact of gamma-tocotrienol on hepatic 3-hydroxy-3-methylglutaryl coenzyme A reductase activity in chickens. J Nutr 1996; 126: 389-394.

24. Takagi K, Okabe S. The effects of drugs on the production and recovery processes of the stress ulcer. Jpn J Pharmacol 1968; 18: 9-18.

25. Konturek SJ, Brzozowski T, Pajdo R, et al. Gastric preconditioning induced by short ischemia: the role of prostaglandins, nitric oxide and adenosine. Med Sci Monit 2001; 7: 610-621.

26. Goto H, Tachi K, Hisanaga Y, et al. Exacerbatory mechanism responsible for water immersion stress-induced gastric lesions in aged rats compared with young rats. Clin Exp Pharmacol Physiol 2001; 28: 659-662

27. Chen CY, Kuo TL, Sheu SY, Kuo TF. Preventive effects of Chinese herb chai-hu-gui-zhi-tang extract on water immersion re- straint stress-induced acute gastric ulceration in rats. J Vet Med Sci 2010; 72: 679-685.

28. Nur Azlina MF, Nafeeza MI, Khalid BA. Effect of tocotrieno on lipid peroxidation in experimental gastritis induced by restraint stress. Pakist J Nutrition 2005b; 4: 69-72.

29. Qodriyah HM, Normadiah K, Gapor MT, Nafeeza MI. Effects of a tocotrienol-rich fraction on indomethacin-induced gastric lesions. Pakist J Clin Nutr 2002; 1: 89-92.

30. Lim SH. The effects of vitamin $\mathrm{E}$ on the expression of adhesion molecules by human umbilical vein endothelial cells, undergraduate thesis for Bsc (biomedical sciences). 2003; 29-43.

31. Qureshi AA, Sami SA, Salser WA, Khan FA. Synergistic effect of tocotrienol-rich fraction (TRF(25)) of rice bran and lovastatin on lipid parameters in humans. J Nutr Biochem 2001; 12: 318-329.

32. Takeuchi K, Aihara E, Sasaki Y, et al. Involvement of cyclooxygenase-1, prostaglandin E2 and EP1 receptors in acid-induced HCO3-secretion in stomach. J Physiol Pharmacol 2006; 57: 661-676.

33. Phillipson M, Johansson ME, Henriksnäs J, et al. The gastric mucus layers: constituents and regulation of accumulation. Am J Physiol Gastrointest Liver Physiol 2008; 295: 806-812.

34. Brzozowski T, Konturek PC, Sliwowski Z, et al. Prostaglandin/cyclooxygenase pathway in ghrelin-induced gastroprotection against ischemia-reperfusion injury. J Pharmacol Exp Ther 2006; 319: 477-487.

35. Takeuchi K, Tanigami M, Amagase K, et al. Endogenous prostaglandin E2 accelerates healing of indomethacin-induced small intestinal lesions through upregulation of vascular endothelial growth factor expression by activation of EP4 receptors. J Gastroenterol Hepatol 2010; 1: S67-74.

36. Hinz B, Brune K. Cyclooxygenase-2 - 10 years later. J Pharmacol Exp Ther 2002; 300: 367-375.

37. Brzozowski T, Konturek PC, Konturek SJ, et al. Expression of cyclooxygenase (COX)-1 and COX-2 in adaptive cytoprotection induced by mild stress. J Physiol Paris 2000; 94: 83-91.

38. Jiang Q, Christen S, Shigenaga MK, Ames BN. Gamma-tocopherol, the major form of vitamin $\mathrm{E}$ in the US diet, deserves more attention. Am J Clin Nutr 2001; 74: 714-722.

39. Ahn KS, Sethi G, Krishnan K, Aggarwal BB. Gamma-Tocotrienol inhibits nuclear factor-kappa B signaling pathway through inhibition of receptor-interacting protein and TAK1 leading to suppression of antiapoptotic gene products and potentiation of apoptosis. J Biol Chem 2007; 282: 809-820.

40. Beharka AA, Han SN, Adolfsson O, et al. Long-term dietary antioxidant supplementation reduces production of selected inflammatory mediators by murine macrophages. Nutr Res 2000; 20: 281-296.

41. Lee E, Choi MK, Lee YJ, et al. Alpha-tocopheryl succinate, in contrast to alpha-tocopherol and alpha-tocopheryl acetate, inhibits prostaglandin E2 production in human lung epithelial cells. Carcinogenesis 2006; 27: 2308-2315.

42. Yam ML, Abdul Hafid SR, Cheng HM, Nesaretnam K. Tocotrienols suppress proinflammatory markers and cyclooxygenase-2 expression in RAW264.7 macrophages. Lipids 2009; 44: 787-797.

\section{Address for correspondence}

\section{Ibrahim Abdel Aziz Ibrahim}

Department of Pharmacology and Toxicology

Faculty of Medicine, Umm Al-Qura University

Makkah 21955 Saudi Arabia

P.O. Box: 7607

fax $(+9662) 5667874$

H/P: (+966) 580030119

e-mail: jjurishi@yahoo.com 